\title{
Adsorption of methylene blue (MB) from aqueous solution using mixed sorbents prepared from Date pit and Olive stone
}

\author{
F. Abed, K. Louhab* \\ Laboratoire de Technologie Alimentaire- Faculty of Enginer Science \\ University of Boumerdes, 35000 - BOUMERDES-ALGERIA
}

*E-mail address: louhab_ka@yahoo.fr

Keywords: recovery; date stones; adsorption; modeling; characterization; methylene blue

\begin{abstract}
The present study focuses on the recovery of the mixed waste food « the date pits and olive stones» in the field of industrial liquid effluent treatment.

The materials was mixed and used in their native form to improve their adsorptive capacity. A rang of physicochemical analysis was performed, for the characterization of adsorbents used, among them: FTIR spectroscopy. In order to test the performances of these adsorbents we are interested in cationic dye the methylene blue considered as pollutant. The effects of several parameters such as contact times, initial concentration of dye, solution $\mathrm{pH}$, and temperature and the proportion of date pits and olive stones in the mixture, were studied in batch system. The result showed that the contact time for removal of all the dyes is about ten minutes, for different concentration of the solution studied colour. For a $\mathrm{pH}$ range that varies between 3 and 10, it was found that a large percentage removal of dye was found for $\mathrm{pH}$ values above 4. Modelling of experimental results was performed using models of Langmuir and Freundlich isotherms, which show that adsorption follows the Langmuir model with high correlation coefficients.
\end{abstract}

\section{INTRODUCTION}

Today, with technological development, and progress that have various vital sectors. The various industrial activities are constantly increasing, and produce liquid effluents, which are often contaminated with toxic and harmful substances.

Among the industries that generate significant pollution, the textile industry which discharges are mostly loaded dyes ( H. Zollinger., 1987,G. Mishra et al., 1993 ) which gives sensation to pollution serious enough. This industry represents only two-thirds of the total production of dyes, about 10 to $15 \%$ of dyes used, are discharged through the effluent (H. Zollinger., 1987).

The latter, loaded with dye, can have harmful effects, and severe impacts in the receiving environment, as they can affect the activity of photosynthesis in aquatic life, due to the reduction of light penetration. And can also be toxic to some aquatic species, due to the presence of aromatic hydrocarbon, metals, and chloride in their constitutions, which are toxic (G. Mishra et al., 1993, I.M. Banat et al., 1996). Thus the removal of dyes from these effluents has become a major environmental concern today ( H. Zollinger., 1987).

Current methods used for disposal, include physicochemical methods such as flocculation, oxidation, ozonation, and reverse osmosis, and biological techniques (T. Robinson et al., 2001). All these methods are different in terms of color removal, operation and financial costs (Khan.A Tabrez et al., 2004.,8 W FC et al., 2001). In recent years researchers are directed to methods of treatment using natural materials such as clays, soft commodities, due to their low cost (Robinson, $\mathrm{T}$ et al., 2001).

The date pites and olive stones are products of agricultural waste, available in our country rejected large amounts annually to the environment. 
In the present work, we opted for recovery of the mixture of by-products of agriculture date pits and olive stones, and their use as adsorbents for the treatment of effluents containing dye, for it was used as a dye methylene blue to test adsorptive capacity of adsorbents.

\section{MATERIALS AND METHODS}

\section{Sorbent preparation}

The date pits were collected from the south of Algeria, and the olive stones were obtained from an olive oil production in the north region of Algeria. These materials used in our study, were first washed several times with tap water to remove dust and dirt adhering, then rinsed with distilled water. They were then exhausted with hexane to remove residual oils and then repeatedly washed with distilled water and dried at $105^{\circ} \mathrm{C}$, then they were crushed.

Once crushed different sample based on a mixture of the two materials were prepared.

For this the two materials were mixed in the following way, we fixed the mass of date pits and vary the mass of olive stone, which will allow us to obtain the samples given in table 1.

Table. 1 : Different proportion of date pits and olive stones in the mixture

\begin{tabular}{|c|c|c|}
\hline Sample number & $\begin{array}{c}\text { Mass of date pits } \\
\text { (g) (DPN) }\end{array}$ & $\begin{array}{c}\text { Mass of olive stone } \\
\text { (g) (OSN) }\end{array}$ \\
\hline 1 & 5 & 1 \\
2 & 5 & 2 \\
3 & 5 & 3 \\
4 & 5 & 4 \\
5 & 5 & 5 \\
6 & 0 & 5 \\
7 & 5 & 0 \\
\hline
\end{tabular}

DPN: date stone in the native state; OSN : olive stone in the native state

The mixture simple of date pits and olive stones were milled with an electric grinder, then sift through a stack of sieves of different mesh openings. The study focused on size fraction between $(80 \mu$ and $630 \mu)$. Then we kept them in desiccators until use.

We worked with the simples in their native state.

Adsorbate : The dye used in this study is a cationic dye is methylene blue (MB), it is chosen because of their strong adsorption on solids.

The chemical structure of methylene blue is shown in Fig1

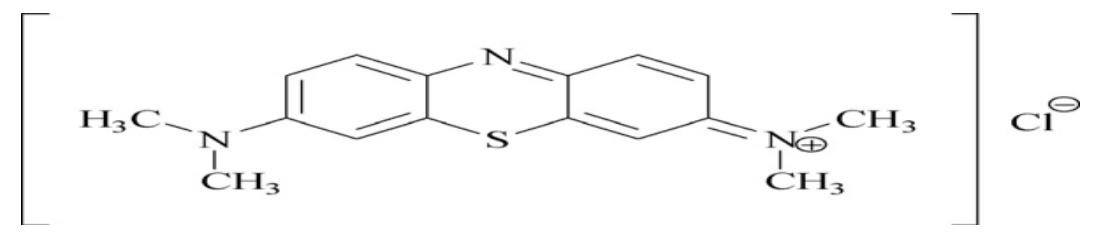

Fig1 Structure of Methylene Blue

The colored solutions are prepared by dissolving dye in distilled water at a concentration of $1000 \mathrm{mg} / 1$. The experimental solutions were obtained by diluting the concentration for the desired concentrations. 
Structural analysis by FTIR spectroscopy: in the range of $[400$ and $4000 \mathrm{~cm}-1]$, were taken in order to find out which functional groups are responsible for the biosorption process. IR spectroscopy analyses were performed using a Fourier transform spectrometer type"'" Nicolet 560 FTIR coupled to a digital computer for the route spectra between [400 and $4000 \mathrm{~cm} \mathrm{-1]}$.

\section{Batch adsorption experiments}

Adsorption equilibrium and kinetic experiments were determined by contacting a known amount of the mixture of date pits and olive stones $(0.1 \mathrm{~g})$, with $30 \mathrm{ml}$ of methylene blue solution (MB) in sealed glass bottles. At $20^{\circ} \mathrm{C}$, pH 5.6 and stirring speed of $300 \mathrm{rpm} / \mathrm{mn}$.

The tests were stopped when equilibrium is reached. The samples are filtered through a filter paper and the concentration is measured by a UV-visible spectrophotometer. The fixed amount of dye per gram of adsorbent is given by the following relation:

$$
\mathrm{q}_{\mathrm{t}}=\left(\mathrm{C}_{\mathrm{i}}-\mathrm{C}_{\mathrm{f}}\right) \mathrm{V} / \mathrm{m}
$$

Where $\mathrm{q}$ is the uptake $(\mathrm{mg} / \mathrm{g}), \mathrm{Ci}$ is the initial methylene blue concentration, $\mathrm{C}_{\mathrm{f}}$ is the final MB concentration $(\mathrm{mg} / \mathrm{g}), \mathrm{V}$ is the solution volume $(\mathrm{ml}), \mathrm{m}$ is the mass $(\mathrm{g})$ of the mixture (date pits and olive stones) .

The effect of initial dye concentration ranging from 50 to $600 \mathrm{mg} / 1$ was studied.

The effect of solution $\mathrm{pH}$ was studied by performing the adsorption experiments of $\mathrm{MB}$ at different $\mathrm{pH}$ levels $(3,4,5,6,7,8,9$ and 10). The solution $\mathrm{pH}$ adjustment was achieved by addition of appropriate amounts of either $0.1 \mathrm{~N} \mathrm{HCl}$ or $0.1 \mathrm{~N} \mathrm{NaOH}$ solutions.

Experiments were conducted at $20,30,40$ and $50^{\circ} \mathrm{C}$ in order to investigate the effect of temperature on the adsorption process. The adsorbent concentration was always kept constant at $100 \mathrm{mg} / 1$ and adsorption was followed till reaching equilibrium.

\section{RESULTS AND DISCUSSION}

\section{IR spectra analysis}

IR analysis of mixture was used to identify some characteristic functional groups of the mixture adsorbent of date pits and olive stones for the adsorption process. The profiles of IR spectroscopy for the mixture of date pits and olives stones was showed in fig. 2

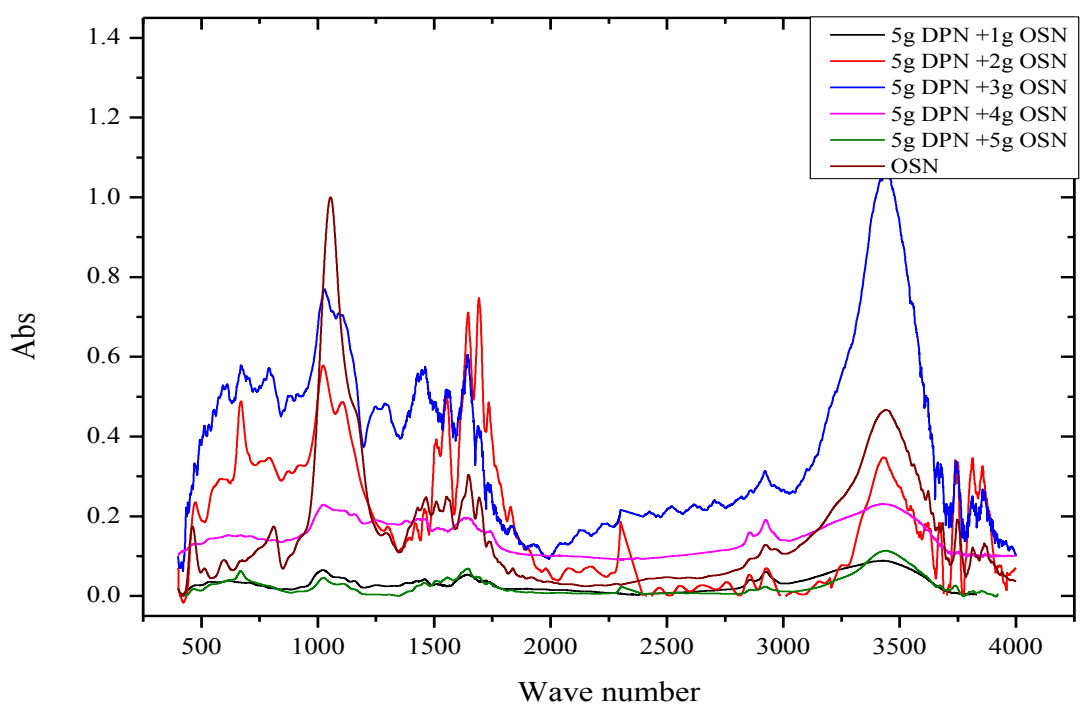

Fig 2 : IR spectroscopy for mixed sorbent (mixture of date pits and olive stones)

(DPN: date stone in the native state, OSN : olive stone in the native state) 


\section{Adsorption isotherm}

The adsorption isotherm indicates how the adsorption molecules distribute between the liquid phase and the solid phase when the adsorption process reaches an equilibrium state. The analysis of the isotherm data by fitting them to different isotherm models is an important step to find the suitable model that can be used for design purpose (B.H. Hameed et all, 2007).

Several models have been published in the literature to describe the experimental data of adsorption isotherms. The Langmuir and Freundlich are the most frequently employed models. In this work, both models were used to describe the relationship between the amount of dye adsorbed and its equilibrium concentration.

\section{Freundlich isotherm}

The Freundlich isotherm describes the non-ideal adsorption of a heterogeneous system and reversible adsorption (Freundlich, 1906). The model can be expressed as

$\mathrm{q}_{\mathrm{e}}=\mathrm{K}_{\mathrm{F}} \mathrm{C}_{\mathrm{e}}^{1 / \mathrm{n}}$

Eq. (1) can be linearized by taking logarithms:

$\mathrm{q}_{\mathrm{e}}=\ln \mathrm{K}_{\mathrm{F}}+1 / \mathrm{n} \ln \mathrm{C}_{\mathrm{e}}$

Where $\mathrm{q}_{\mathrm{e}}$ is the amount of dye adsorbed per unit of adsorbent $(\mathrm{mg} \cdot \mathrm{g}-1), \mathrm{C}_{\mathrm{e}}$ is the concentration of dye solution at adsorption equilibrium $(\mathrm{mg} \cdot \mathrm{L}-1)$, and $\mathrm{K}_{\mathrm{F}}(\mathrm{L} \cdot \mathrm{g}-1)$ and $\mathrm{n}$ is the Freundlich adsorption isotherm constants. The result of adsorption isotherms modelling by freundlich model were represented in fig 3, The favourable adsorption in this model can be

characterized by the fact that if a value for $\mathrm{n}$ is above unity, adsorption is favourable and a physical process.(N.Babakhouya et al, 2010).

Table 2 indicated that the value of $n$ varies between 4 and 6 at different proportion of the mixture of date pits and olive stones, this indicated favourable sorption of dye onto the different mixture of waste materials.

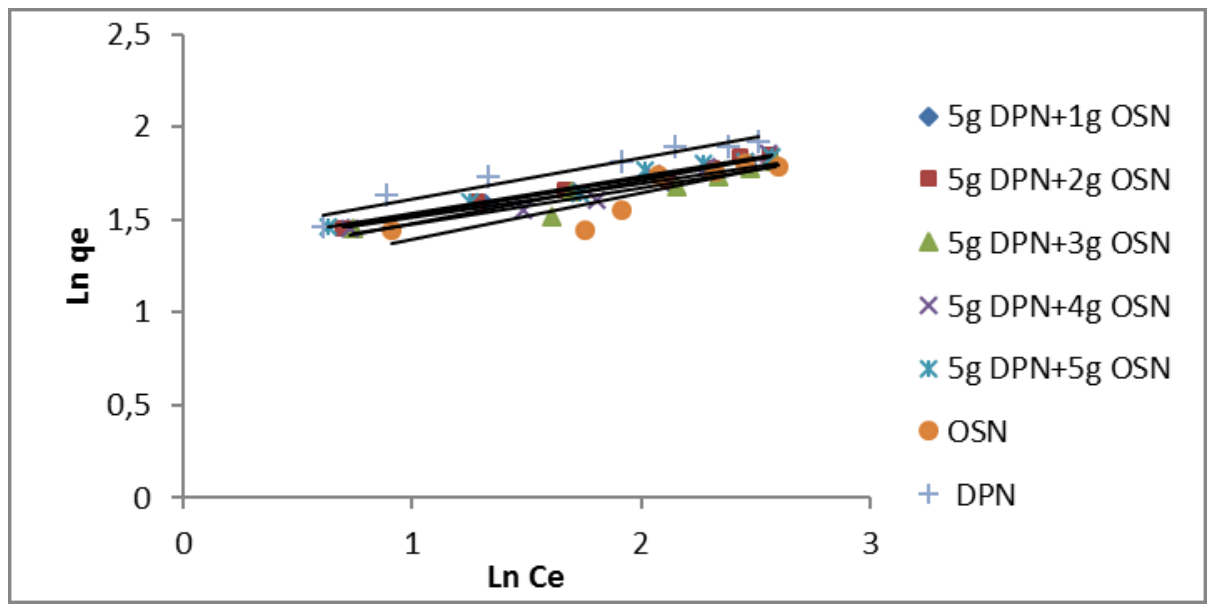

Fig3 : Freundlich plot for adsorption of MB on différent mixed sorbent 


\section{Langmuir isotherm}

Langmuir's isotherm model suggests that uptake occurs on homogeneous surface by monolayer sorption without interaction between sorbed molecules. The model assumes uniform energies of adsorption onto the surface and no transmigration of adsorbate in the plane of the surface. The linear form of Langmuir isotherm equation is represented by the following equation (M.Gouamid et al, 2013)

$$
\mathrm{C}_{\mathrm{e}} / \mathrm{q}_{\mathrm{e}}=1 / \mathrm{bQ}+\mathrm{C}_{\mathrm{e}} / \mathrm{Q}
$$

where qe is the amount adsorbed at equilibrium time $(\mathrm{mg} / \mathrm{g}), \mathrm{C}_{\mathrm{e}}$ is the equilibrium concentration of the adsorbate ions $(\mathrm{mg} / \mathrm{L}), \mathrm{Q}$ and $\mathrm{b}$ are Langmuir constants related to maximum adsorption capacity (monolayer capacity) and energy of adsorption, respectively. When $\mathrm{Ce} / \mathrm{qe}$ is plotted against $\mathrm{Ce}, \mathrm{a}$ straight line with slope 1/Q and intercepts 1/bQ is obtained (Fig.4).

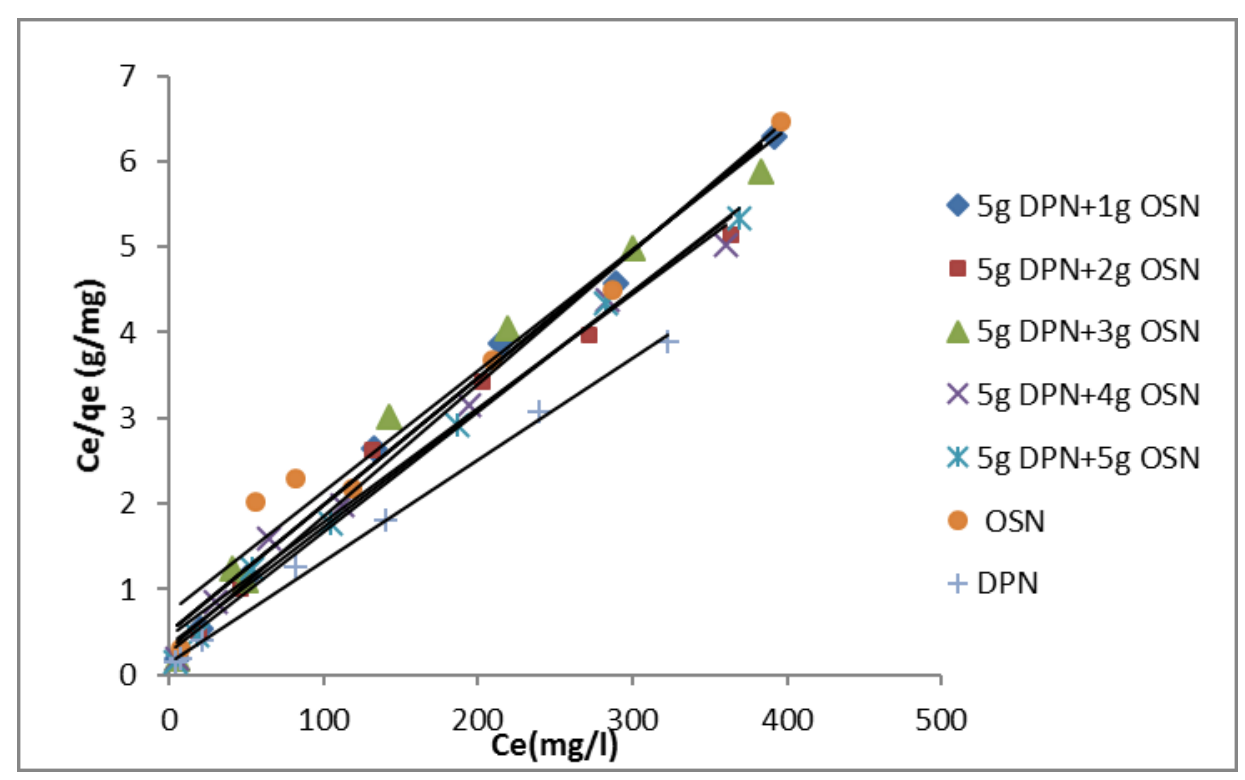

Fig 4 : Langmuir isotherm plot for the adsorption of $\mathrm{MB}$ on different mixture adsorbent

The essential characteristics of the Langmuir equation can be expressed in terms of a dimensionless separation factor, $\mathrm{R}_{\mathrm{L}}$, defined as [Deepak pathania et al,2013)]:

$$
\mathrm{R}_{\mathrm{L}}=1 /(1+\mathrm{bC})
$$

where $\mathrm{C}_{0}$ is the highest initial solute concentration, $\mathrm{b}$ is the Langmuir's adsorption constant $(\mathrm{L} / \mathrm{mg})$. The $\mathrm{R}_{\mathrm{L}}$ value implies the adsorption to be unfavorable $\left(\mathrm{R}_{\mathrm{L}}>1\right)$, linear $\left(\mathrm{R}_{\mathrm{L}}=1\right)$, favourable $\left(0<\mathrm{R}_{\mathrm{L}}\right.$ $<1)$ or irreversible $\left(\mathrm{R}_{\mathrm{L}}=0\right)$.

Value of $\mathrm{R}_{\mathrm{L}}$ were varied in the rang of 0.045 and 0.078 with several proportion of mixed adsorbent. The value of $\mathrm{R}_{\mathrm{L}}$ is between 0 and 1 showed that the adsorption of MB was favourable with the different mixture of date pits and olive stones used. Maximum theorical uptake upon complete saturation of the surface of the mixture $(5 \mathrm{~g}$ DPN $+1 \mathrm{~g}$ OSN) of date pit and olive stone was obtained to be 75,188 compared to 70,4225 for olive stone only. 
Table 2 : Langumuir and Frendlich isotherm constants for methylene blue onto different proportion of mixture of date pits and olive stones

\begin{tabular}{|c|c|c|c|c|c|c|c|}
\hline \multirow[t]{2}{*}{ Mixed adsorbent } & \multicolumn{4}{|c|}{ Langmuir parameter } & \multicolumn{3}{|c|}{ Freundlich parameter } \\
\hline & $q m(\mathrm{mg} / \mathrm{g})$ & b x $10^{\wedge} 2$ & $\mathbf{R 2}$ & $\operatorname{RLx} 10^{\wedge} 2$ & KF & $1 / \mathbf{n}$ & $\mathbf{R 2}$ \\
\hline $5 \mathrm{~g} \mathrm{DPN}+1 \mathrm{~g} \mathrm{OSN}$ & 64,5161 & 5,08 & 0,9922 & 4,6916 & 21,6023 & 0,1805 & 0,9845 \\
\hline $5 \mathrm{~g} \mathrm{DPN}+2 \mathrm{~g} \mathrm{OSN}$ & 72,9927 & 3,77 & 0,9805 & 6,2206 & 20,7539 & 0,203 & 0,972 \\
\hline $5 \mathrm{~g} \mathrm{DPN}+3 \mathrm{~g}$ OSN & 67,1141 & 3 & 0,9811 & 7,6885 & 19,0283 & 0,1962 & 0,9018 \\
\hline $5 \mathrm{~g}$ DPN $+4 \mathrm{~g}$ OSN & 75,188 & 2,95 & 0,9859 & 7,8197 & 17,7828 & 0,23 & 0,948 \\
\hline $5 \mathrm{~g} \mathrm{DPN}+5 \mathrm{~g}$ OSN & 70,922 & 5,24 & 0,9955 & 4,5572 & 21,513 & 0,2008 & 0,9742 \\
\hline OSN & 70,4225 & 1,98 & 0,9637 & 11,2112 & 13,9701 & 0,2499 & 0,7664 \\
\hline DPN & 84,7458 & 3,09 & 0,9969 & 7,84 & 24,6547 & 0,2199 & 0,9409 \\
\hline
\end{tabular}

OSN : olive stone in native state. DPN : date pit in native state

\section{Adsorption kinetics}

The figure shows the evolution of the adsorbed amount with time. The adsorption of the dye (MB) on different mixture of adsorbents used has the same gaits characterized by a strong adsorption on the first few minutes of contact. According to the figures, in the first 10 minutes, the percentage removal of methylene blue was fast. After it stabilizes and reaches equilibrium. The first rapid phase may be due to the availability of vacant adsorption site at initial stage. The high percentage of elimination of dye was observed in the mixture $(5 \mathrm{~g}$ DPN $+5 \mathrm{~g} \mathrm{GON})$ with $29.029 \mathrm{mg} / \mathrm{g}$ compared to the mixture (5g DPN+ $3 \mathrm{~g}$ OSN) with $27.536 \mathrm{mg} / \mathrm{g}$. and the uptake for olive stone only was $24,7237 \mathrm{mg} / \mathrm{g}$,

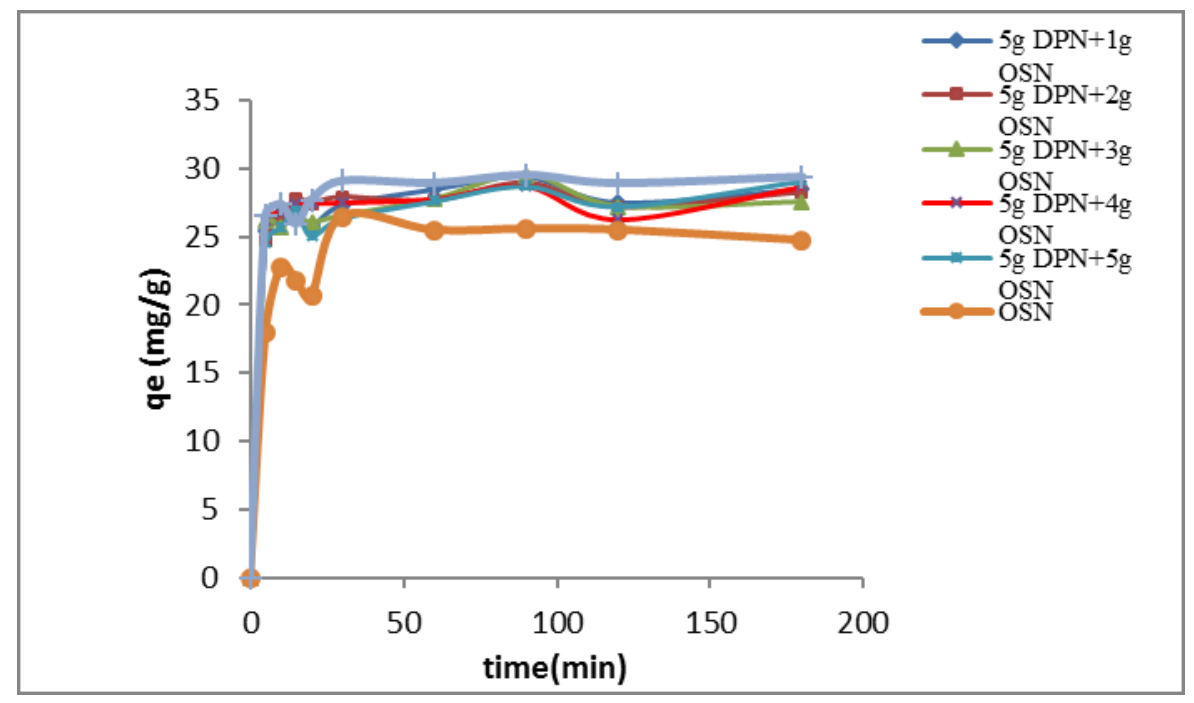

Fig 2 : The effect of contact time to the adsorption rate of MB by the mixture of adsorbents 
in order to investigate the mechanism of adsorption, the kinetic data were treated with the pseudosecond order kinetic model. The differential equation is the following:

$$
\mathrm{dq}_{\mathrm{t}} / \mathrm{dt}=\mathrm{k}_{2}\left(\mathrm{q}_{\mathrm{e}}-\mathrm{q}_{\mathrm{t}}\right)^{2}
$$

where $\mathrm{k}_{2}$ is the equilibrium rate constant of pseudosecond- order adsorption ( $\left.\mathrm{g} / \mathrm{mg} \mathrm{min}\right)$. Integrating Eq. (5) for the boundary condition $t=0$ to $t$ and $q_{t}=0$ to $q_{t}$, gives the following:

$$
1 /\left(q_{e}-q_{t}\right)=1 / q_{e}+k_{2} t
$$

which is the integrated rate law for a pseudo-second-order reaction. Eq. (6) can be rearranged to obtain a linear form:

$$
\mathrm{t} / \mathrm{q}=1 /\left(\mathrm{k}_{2} \mathrm{q}_{\mathrm{e}}^{2}\right)+\left(1 / \mathrm{q}_{\mathrm{e}}\right) \mathrm{t}
$$

The slope and intercept of the plot of $t$ /qt versus $t$ were used to calculate the second-order rate constant, k2 (Fig. 3). It is more likely to predict the behavior over the whole range of adsorption for the case of chemisorption mechanism as the rate controlling step

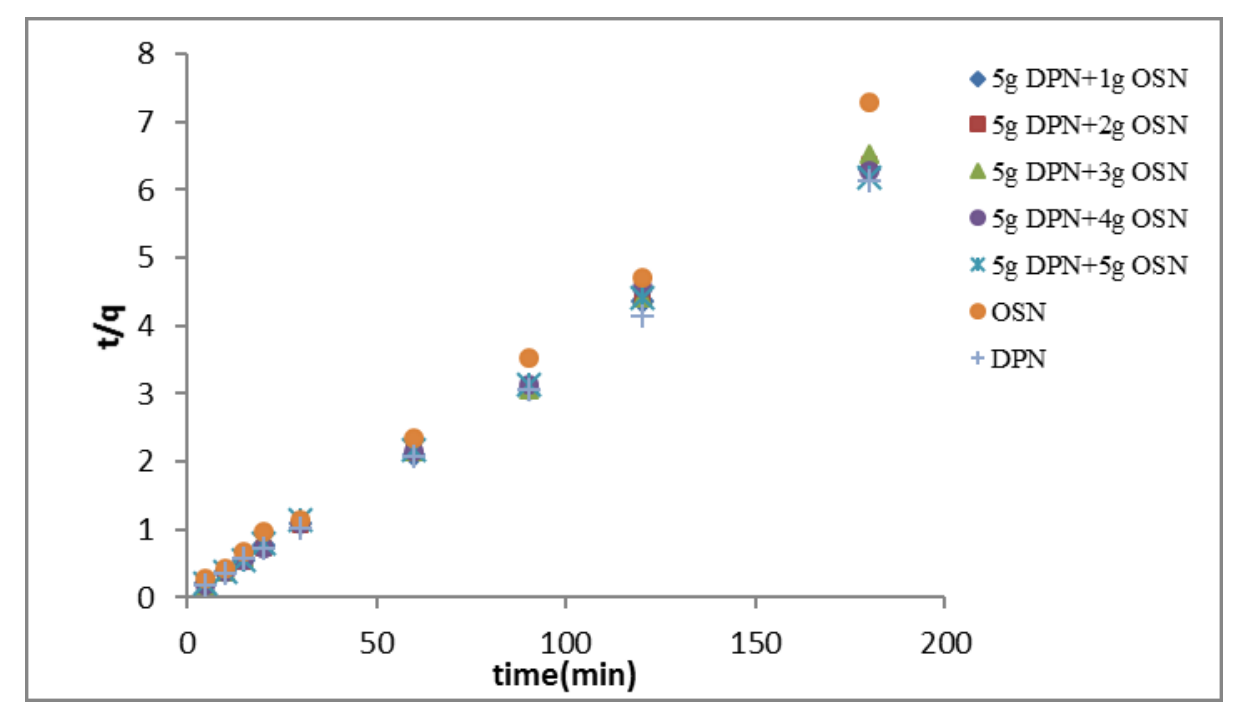

Fig 3 : Pseudo second order kinetics of $\mathrm{MB}$ by the mixed sorbent $\left(\mathrm{C}=100 \mathrm{mg} / 1, \mathrm{~T}=20^{\circ} \mathrm{C}\right)$

Table 3 lists the results of the rate constant studies for different initial dye concentrations by the second-order models. The correlation coefficient, R2 for the pseudo-second-order adsorption model has high value ( $>99 \%$ ), and its calculated equilibrium adsorption capacity, qe,cal is consistent with experimental data. These facts suggest that the pseudo-second-order adsorption mechanism is predominant, and that the overall rate of the dye adsorption process appears to be controlled by the chemisorption process. 
Table 3 : Pseudo-second order kinetics model parameters for MB sorption onto the mixture of date pits and olive stones

\begin{tabular}{|c|c|c|c|c|}
\cline { 2 - 5 } \multicolumn{1}{c|}{} & \multicolumn{3}{c|}{ Equation pseudo seconde ordre } \\
\hline $\begin{array}{c}\text { proportion of the } \\
\text { mixture }\end{array}$ & $\begin{array}{c}\text { qe,exp } \\
(\mathrm{mg} / \mathrm{g})\end{array}$ & $\begin{array}{c}\text { qe,cal } \\
(\mathrm{mg} / \mathrm{g})\end{array}$ & $\begin{array}{c}\mathrm{k} 2 \\
(\mathrm{~g} / \mathrm{mg}, \mathrm{min})\end{array}$ & $\mathrm{R} 2$ \\
\hline $5 \mathrm{~g}$ DPN+1g OSN & 28,5033 & 28,5714 & 0,0406 & 0,999 \\
\hline $5 \mathrm{~g}$ DPN+2g OSN & 28,2455 & 28,169 & 0,0708 & 0,9991 \\
\hline $5 \mathrm{~g}$ DPN+3g OSN & 27,5369 & 27,7778 & 0,0932 & 0,9986 \\
\hline $5 \mathrm{~g}$ DPN+4g OSN & 28,6965 & 28,169 & 0,0435 & 0,9971 \\
\hline $5 \mathrm{~g}$ DPN+5g OSN & 29,0831 & 28,9017 & 0,016 & 0,9984 \\
\hline OSN & 24,7237 & 25,2525 & 0,0342 & 0,9986 \\
\hline DSN & 29,3837 & 29,4985 & 0,0333 & 0,9998 \\
\hline
\end{tabular}

\section{The effect of pH of the solution}

the effect of the dye solution plays an important role in the whole adsorption process, particularly on adsorption capacity. The effect of $\mathrm{pH}$ is studied for an initial concentration of $100 \mathrm{mg} / 1$. The $\mathrm{pH}$ range is selected between [ 3-10 ] . (Fig 5) shows that the adsorption capacity is minimum at $\mathrm{pH}=$ 3 , and increases with increasing $\mathrm{pH}$ up to $\mathrm{pH}=4$ and then remains almost constant between $\mathrm{pH}$ values between 4 and 10 . At acidic $\mathrm{pH}$, the adsorption capacity is low, this is due to the presence of excess $\mathrm{H}+$ ions, which are competing with dye cations $\mathrm{BM}+$ for adsorption sites, which causes the decrease adsorption capacity .

At high $\mathrm{pH}$, greater than 4 , the surface of the adsorbent can become negatively charged, there by improving the electrostatic attractive forces between the surface of the adsorbent and the BM + cations. Then the acid $\mathrm{pH}$ is unfavorable for the adsorption of methylene blue. (Fawzi Banat et al, 2003.,Oualid Hamdaoui,2006) .

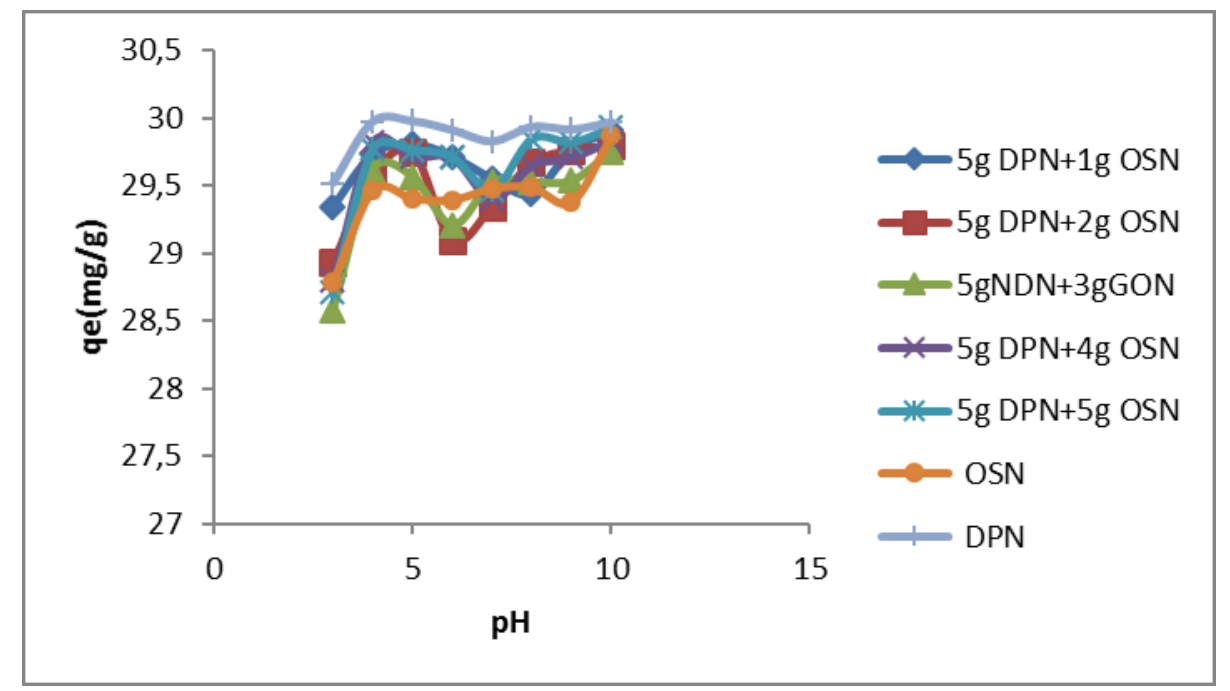

Fig 5 : Effect of initial $\mathrm{pH}$ in the dye sorption capacity by the mixed sorbent $(\mathrm{C}=100 \mathrm{mg} / \mathrm{l}$, $\left.\mathrm{T}=20^{\circ} \mathrm{C}\right)$

\section{Adsorption thermodynamic}

The thermodynamic parameters for the adsorption process, the standard free energy, standard enthalpy and standard entropy were calculated using the following equations (Zhang Jian et al, 2013) 
$\Delta \mathrm{G}=-\mathrm{RT} \ln \mathrm{K}_{\mathrm{L}}$

$\Delta \mathrm{G}=\Delta \mathrm{H}-\mathrm{T} \Delta \mathrm{S}$

$\ln \mathrm{K}_{\mathrm{L}}=\Delta \mathrm{S} / \mathrm{R}-\Delta \mathrm{H} / \mathrm{RT}$

where $\Delta \mathrm{G}$ is the standard free energy, $\mathrm{kJ} \mathrm{mol}^{-1} ; \mathrm{R}$ is the universal gas constant, $8.314 \mathrm{~J} \mathrm{~mol}^{-1} \mathrm{~K}^{-1}$; $\mathrm{T}$ is the absolute solution temperature, $\mathrm{K} ; \Delta \mathrm{H}$ is the standard enthalpy, $\mathrm{kJ} \mathrm{mol}^{-1} ; \Delta \mathrm{S}$ is the standard entropy. The standard enthalpy and standard entropy values can be calculated from the slope and intercept of the plot of $\ln K_{\mathrm{L}}$ versus $1 / \mathrm{T}$ as shown in Fig. 6. The values of these parameters were calculated using Eqs. (5), (6) and (7). at various temperature and were shown in Table 4.

Table 4 showed that the value of $\mathrm{H}$ was positive indicating the endothermic nature of the adsorption of methylene blue onto the mixture ( $5 \mathrm{~g}$ DPN+1g OSN) different temperature. And the value of $\mathrm{H}$ was negative for all the rest of mixture sorbent indicate an exothermic process, similar result has been reported by (Vipasiri vimonses et al, 2009). The positive value of $S$ inferred the affinity of the mixture (5g DPN+1g OSN) adsorbent for methylene blue as a result of the increased randomness at the interface between the solid-liquid phases, but for the rest of mixture adsorbent, the negative valus of $\mathrm{S}$ suggest a decrease in randomness at their solid/solution interface and no significant changes occur in the internal structure of the adsorbents through the adsorption. (Vipasiri vimonses et al, 2009., Necip Atar et al, 2007)

In general, the range of standard free energy for physisorption is in a range of -20 to $0 \mathrm{kj} / \mathrm{mol}$, and the chimisorption varies between -80 and $-400 \mathrm{kj} / \mathrm{mol}$ (Vipasiri vimonses et al, 2009)

The values of $G$ were all negative at difference temperature, for all mixture adsorbent indicating that the adsorption was spontaneous and physical.

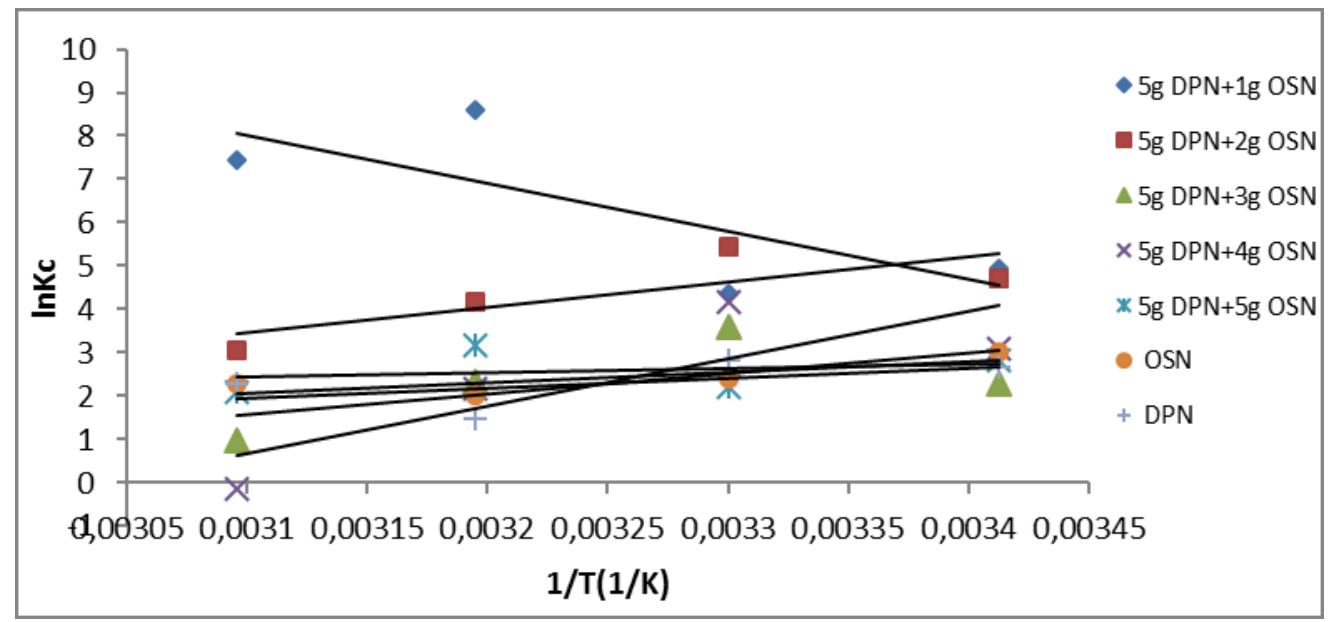

Fig6 : Relation between equilibrium constant $(\mathrm{Kc})$ and temperature $\left(\mathrm{C}_{0}=100 \mathrm{mg} / \mathrm{l}\right)$ 
Table 4: Value of the thermodynamic of adsorption at various temperatures and for different proportion of mixture $\left(\mathrm{C}_{0}=100 \mathrm{mg} / \mathrm{l}\right)$

\begin{tabular}{|c|c|c|c|c|}
\hline mixed sorbent & $\mathrm{T}^{\circ}\left({ }^{\circ} \mathrm{C}\right)$ & $\Delta \mathbf{G}^{\circ}(\mathrm{Kj} / \mathrm{mol})$ & $\Delta \mathrm{H}^{\circ}(\mathrm{KJ} / \mathrm{mol})$ & $\Delta S^{\circ}(\mathrm{Kj} / \mathrm{molK})$ \\
\hline \multirow[b]{4}{*}{$5 \mathrm{~g} \mathrm{DPN}+1 \mathrm{~g}$ OSN } & 293 & $-8,078$ & \multirow[b]{4}{*}{93,059} & \multirow[b]{4}{*}{0,342} \\
\hline & 303 & $-6,821$ & & \\
\hline & 313 & $-18,205$ & & \\
\hline & 323 & $-15,633$ & & \\
\hline \multirow[b]{4}{*}{$5 \mathrm{~g} \mathrm{DPN}+2 \mathrm{~g}$ OSN } & 293 & $-7,459$ & \multirow[b]{4}{*}{$-52,831$} & \multirow[b]{4}{*}{$-0,15$} \\
\hline & 303 & $-9,644$ & & \\
\hline & 313 & $-6,49$ & & \\
\hline & 323 & $-3,283$ & & \\
\hline \multirow[b]{4}{*}{$5 \mathrm{~g} \mathrm{DPN}+3 \mathrm{~g}$ OSN } & 293 & $-5,546$ & \multirow[b]{4}{*}{$-39,304$} & \multirow[b]{4}{*}{$-0,109$} \\
\hline & 303 & $-9,041$ & & \\
\hline & 313 & $-6,02$ & & \\
\hline & 323 & $-2,626$ & & \\
\hline \multirow[b]{4}{*}{$5 \mathrm{~g} \mathrm{DPN}+4 \mathrm{~g}$ OSN } & 293 & $-7,548$ & \multirow[b]{4}{*}{$-90,381$} & \multirow[b]{4}{*}{$-0,275$} \\
\hline & 303 & $-10,512$ & & \\
\hline & 313 & $-5,625$ & & \\
\hline & 323 & 0,366 & & \\
\hline \multirow[b]{4}{*}{$5 \mathrm{~g} \mathrm{DPN}+5 \mathrm{~g}$ OSN } & 293 & $-6,839$ & \multirow[b]{4}{*}{$-8,643$} & \multirow[b]{4}{*}{$-0,007$} \\
\hline & 303 & $-5,587$ & & \\
\hline & 313 & $-8,296$ & & \\
\hline & 323 & $-5,66$ & & \\
\hline \multirow[b]{4}{*}{ OSN } & 293 & $-7,345$ & \multirow[b]{4}{*}{$-21,103$} & \multirow[b]{4}{*}{$-0,048$} \\
\hline & 303 & $-6,072$ & & \\
\hline & 313 & $-5,247$ & & \\
\hline & 323 & $-6,098$ & & \\
\hline \multirow[b]{4}{*}{ DPN } & 293 & $-6,472$ & \multirow[b]{4}{*}{$-19,55$} & \multirow[b]{4}{*}{$-0,044$} \\
\hline & 303 & $-7,096$ & & \\
\hline & 313 & $-3,794$ & & \\
\hline & 323 & $-6,163$ & & \\
\hline
\end{tabular}

\section{CONCLUSION}

The aim of this work was the preparation of an adsorbent by mixing the two adsorbents date pits and olive stones to improve their adsorptive capacity. The mixed sorbent were investigated for the removal of basic dye namely methylene blue from aqueous solution.

The adsorption equilibrium of methylene blue onto the mixture of date pits and olive stone was represented by Langmuir and Freundlich isotherm, the adsorption isotherm data were well fitted by the Langmuir model. And the thermodynamic study shows that the sorption onto the mixture of date pit and olive stone was spontaneous and exothermic. 


\section{References}

[1] H. Zollinger., 1987. Color Chemistry - Synthesis, Properties and Application of Organic Dyes and Pigments, VCH Publishers, New Yourk.

[2] S. Souabi., 1996. Techniques Sciences Méthodes 3, 181.

[3] G. Mishra., M. Tripathy., 1993. A critical review of the treatment for decolourization of textile effluent. Colourage. 40, 35-38.

[4] I.M. Banat., P. Nigam., D. Singh., R. Marchant., 1996. Microbial decolourization of textile-dye containing effluents. a review, Bioresour. Technol. 58, 217-227.

[5] H. Zollinger., 1987. Azo dyes and pigments, in: Colour Chemistry-Synthesis, Properties and Applications of Organic Dyes and Pigments, VCH, New York, pp. 92-100.

[6] T. Robinson., G. Mcmullan., R. Marchant., P. Nigam., 2001. Remediation of dyes in textile effluent: a critical review on current treatment technologies with a proposed alternative, Bioresour. Technol. 77, 247- 255.

[7] Khan.A Tabrez., Singh.V., Kumar D., 2004. Removal of some basic dyes from artificial textile wastewater by adsorption on Akash Kinari coal. J Sci Ind Res. 63, 355-364.

[8] W FC., Tseng RL., Juang RS., 2001. Adsorption of dyes and phenols from water on the activated carbons prepared from corn cob wastes. Environ Technol. 22, 205-213.

[9] Robinson, T., Marchant, R., Nigam, P., 2001. Remediation of dyes in textile effluent: a critical review on current treatment technologies with a proposed alternative. Bioresource Technology. 77, 247-255.

[10]Freundlich,H.M.F ; 1906 Over the adsorption in solution.J. Phys.Chem.57, 385-470.

[11]Babakhouya.N, H. Aksas, S. Bougharara and K.Louhab. Adsorption of Cd(II) ions fron aqueos solution using mixed sorbents prepared from olive stone and date pits. Journal of applied sciences 10 (19) : 2316-2321, 2010).

[12]M.Gouamid, M.R.Ouahrani, M.B.Bensaci. Adsorption equilibrium, kinetics and thermodynamics of methylene blue from aqueos solutions using date palm leaves. Energy procedia 36 (2013) 898-907)

[13]Deepak pathania, Shikha Sharma, Pardeep Singh. Removal of methylene blue by adsorption onto activated carbon developed from Ficus carica bast. Arabian journal of Xhimistry (2013)

[14]Fawzi Banat,Sameer Al-Asheh, Leema Al-Makhadmeh. Evaluation of the raw and activated date pits as potential asorbents for dye containing waters. Process biochimistry 39 (2003) 193202

[15] Oualid Hamdaoui. Batch study of liquid- phase adsorption of methylene blue using sedar sawdust and crushed brick. Journal of Hazardous materials b135 (2006) 264-273)

[16]Zhang Jian, Ping Qingwei,Niu Meihong, Shi Haiqiang,Li Na. Kinetics and equilibrium studies from the methylene blue adsorption on diatomite treated with sodium hydroxyde. Applied clay science 83-84(2013)12-16)

[17] Vipasiri vimonses, Shaomin lei, Bo jin, Chris w.k. Chow, chris saint, adsorption of congo red by three australian kaolins, applied clay science 43 (2009) 465-472.

[18]Necip Atar, Asim Olgun Removal of acid blue 062 on aqueos solution using calcinated colemanite ore waste, journal of hazardous materials 146 (2007) 171-179,

[19] Vipasiri vimonses, Shaomin lei, Bo jin, Chris w.k. Chow, chris saint, kinetic study and equilibrium isotherm analysis of congo red adsorption by clay materials, chemical engineering journal 148 (2009) 354-364.

[20]B.H. Hameed*, A.L. Ahmad, K.N.A. Latiff., Adsorption of basic dye (methylene blue) onto activated carbon prepared from rattan sawdust, Dyes and Pigments 75 (2007) 143-149 